\title{
ORIGIN OF PORE-LINING CHLORITE IN THE AEOLIAN ROTLIEGEND OF NORTHERN GERMANY
}

\author{
S. HILLIER*, A. E. FALLICK ${ }^{\dagger}$ AND A. MATTER \\ Geologisches Institut, Universität Bern, Baltzerstrasse 1, 3012, Switzerland, and ${ }^{\dagger}$ Isotope Geosciences Unit, Scottish \\ Universities Research and Reactor Centre, East Kilbride, Glasgow, G750QU, Scotland
}

(Received 12 May 1995; revised 11 October 1995)

\begin{abstract}
A B STRACT: Pore-lining chlorite is common in Rotliegend lake shoreline aeolian sandstones from northern Germany and preserves abnormally high primary intergranular porosity. In the north of the study area, in a basinward direction, the chlorites are $\mathrm{Mg}$-rich while towards the south they become Fe-rich over a distance of about $15 \mathrm{~km}$. All are unusually rich in $\mathrm{Mn}$. Magnesium-rich examples tend to be more abundant than illite, while Fe-rich examples cover framework grains less continuously and are admixed with more abundant illite. Oxygen isotope analysis of 30 chlorites in the $2-6 \mu \mathrm{m}$ fraction gave $\delta^{18} \mathrm{O}$ (SMOW) values of 7 to $12 \%$ (mean 9.8\%). These data show no obvious trend across the study area, nor in relation to changes in chlorite composition, or burial depth.

The honeycomb arrangement of chlorite crystals suggests chlorite formation via the sequence smectite-corrensite-chlorite. Chlorite distribution and the systematic changes in its composition suggest that formation of a precursor was related to lateral migration of $\mathrm{Mg}$-rich fluids from basinal shales and/or evaporites during shallow burial. Interaction of these fluids with early formed oxyhydroxide coatings on the aeolian sand grains provided a source of $\mathrm{Fe}$ and the $\mathrm{Mn}$. The isotope data suggest that the eventual formation of chlorite during deep burial occurred from waters with positive $\delta^{18} \mathrm{O}$ values, comparable to those present during the deep burial formation of illite.
\end{abstract}

Most studies concerned with clay minerals in the Permian Rotliegend of Western Europe have focused on the various forms of the illite that is so common in these rocks (e.g. Rossel, 1982; Lee et al., 1989; Warren \& Curtis 1989; Robinson et al., 1993; Ziegler et al., 1994). Apart from its abundance, this is also because of the extremely detrimental effect that illite, particularly fibrous illite, may have on permeability, and therefore on hydrocarbon reservoir quality. Other clay minerals such as chlorite are only rarely mentioned. However, in the region of northwest Germany, certain parts of the Rotliegend are characterized by the presence of abundant pore-lining chlorite (Platt, 1993; Gaupp et al., 1993; Hillier, 1994) and also much less illite than elsewhere. In addition to the reduced amounts of illite, the presence of porelining chlorite is itself beneficial to hydrocarbon reservoir quality because it has resulted in the

*Present address: Macaulay Land Use Research Institute, Craigiebuckler, Aberdeen AB $158 \mathrm{QH}$, Scotland preservation of primary porosity that is $5-10 \%$ higher than in adjacent sandstones where chlorite is absent (Platt, 1993). Indeed, sandstones with porelining chlorite have the highest porosities of any Rotliegend sandstones in this region (Gaupp et al., 1993) and often in amounts that are anomalously high for the $4-5 \mathrm{~km}$ depths to which the Rotliegend is buried. For example, 20\% porosity at $5 \mathrm{~km}$ depth is not uncommon. The purpose of this study is to describe the occurrence and characteristics of these chlorites in more detail than in previous work, and to interpret these data in terms of the origin of the chlorite. In addition, the conclusions have potential implications for the occurrence of anomalously high porosity sandstones in this and other areas of the Rotliegend.

\section{LOCATION AND GEOLOGICAL SETTING}

The study area is located in northwest Germany to the north of Hannover (Fig. 1) and corresponds to the area containing boreholes $F$ to $I$ as studied by 


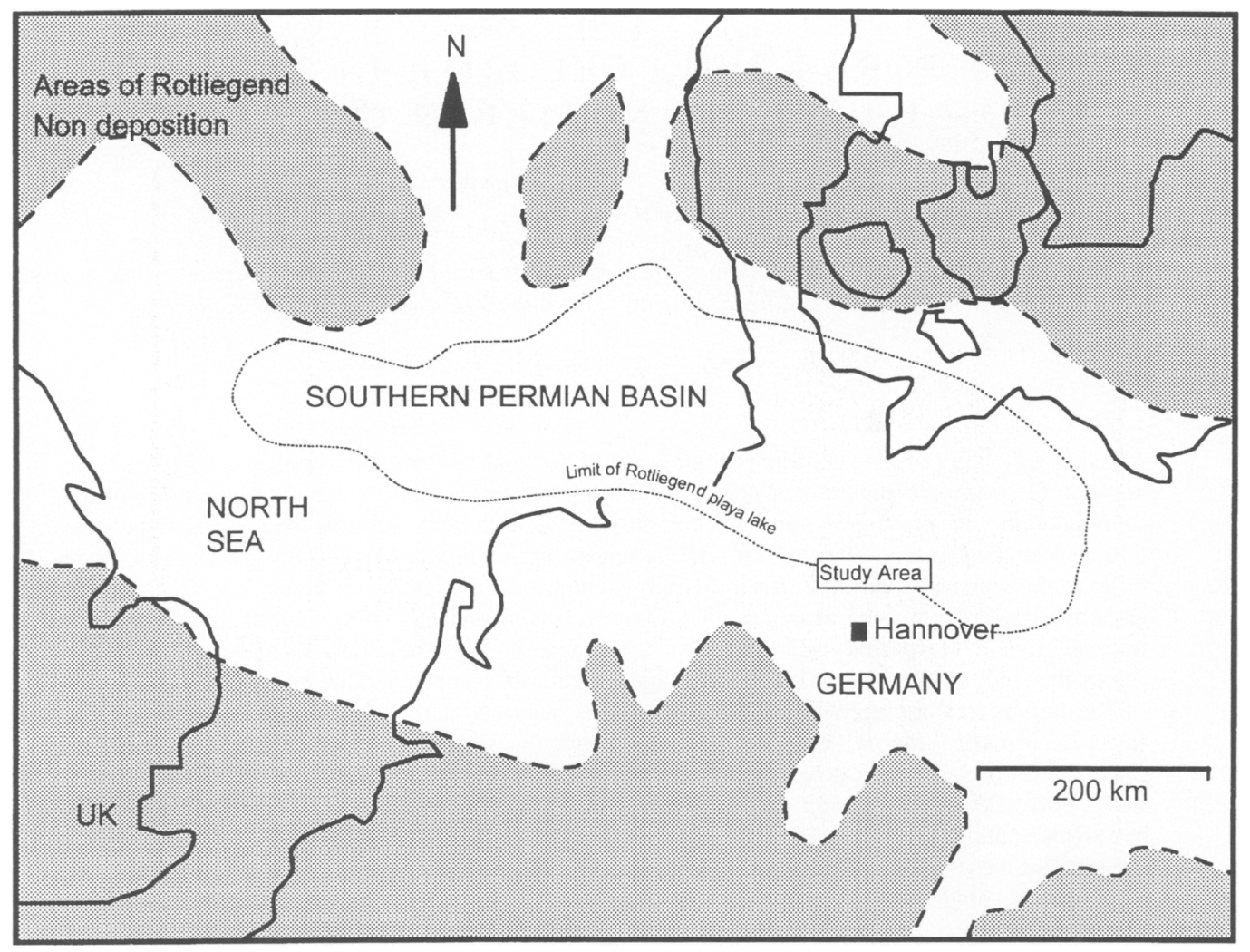

FIG. 1. Location and Permian palaeogeography of the study area.

Platt (1993, 1994). Palaeogeographically, it lies in the southeast corner of the Southern Permian Basin, more or less along the southern margin of the perennial Rotliegend saline lake which occupied the basin centre (Fig. 1). The Southern Permian Basin formed as a foreland basin along the northern margin of the Variscan Mountains (Glennie, 1990). Stratigraphically, the Rotliegend in the study area is divided into three formations (Fig. 2) (Gast, 1991). The oldest Schneverdingen Formation was deposited unconformably on Carboniferous Coal Measures and Permian volcanics. It consists of aeolian and alluvial fan facies and is locally variable in thickness and facies composition as its deposition was controlled by a system of northsouth trending graben. The Schneverdingen Formation is succeeded by the Slochteren Formation. In the study area the Slochteren Formation is dominated by aeolian dune and interdune facies and is equivalent to the Leman Sandstone of the southern North Sea (Glennie,
1990). Marine fossils identified in cores show that by the beginning of the deposition of the Slochteren Formation a connection was established between the Rotliegend lake basin and the open ocean (Gast, 1991).

The overlying Hannover Formation consists of alternations of red mudstones, siltstones and sandstones. The mudstones and siltstones are the deposits of mudflats, evaporitic sabkhas, and the Rotliegend saline lake which repeatedly, and increasingly, transgressed into the study area through time (Gast, 1991). The Wustrow Sandstone Member occurs towards the base of the formation, and varies from a few to over $10 \mathrm{~m}$ in thickness in the study area. It is the most prominent sandstone in the generally fine-grained Hannover Formation, (Fig. 2). Such sandstones, the Wustrow Member in particular, were referred to in previous studies as 'shoreline' sandstones (Gast, 1991; Platt, 1993, 1994; Gaupp et al., 1993) and it is here that pore-lining chlorite is most often well developed. 


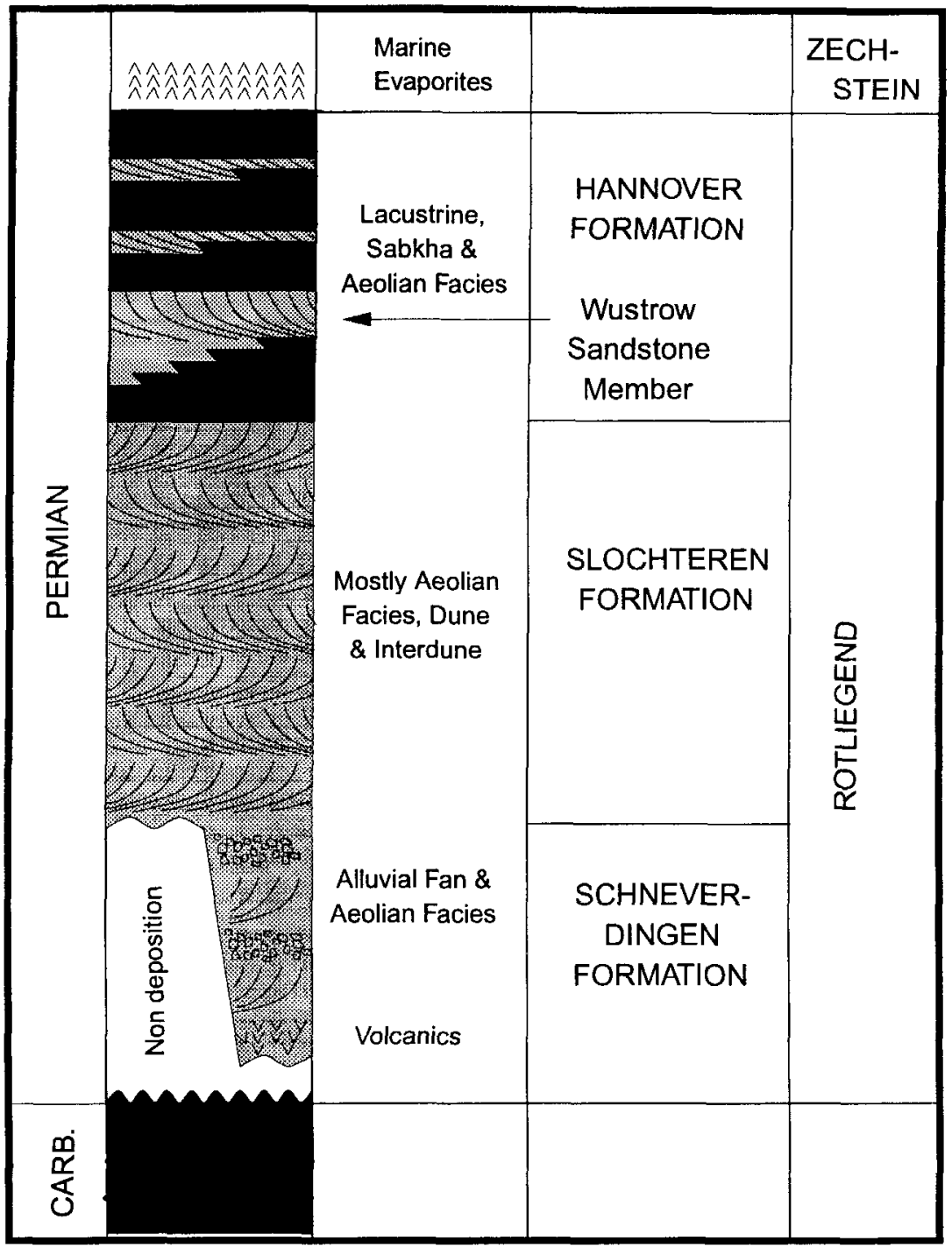

FIG. 2. Generalized stratigraphy of the study area. Most of the samples analysed are from the Wustrow Sandstone member of the Hannover Formation.

Based on its occurrence in 'shoreline' sandstones and its Mg-rich chemistry, Gaupp et al. (1993) and Platt (1993) concluded that chlorite formation was related to the expulsion of $\mathrm{Mg}$-rich fluids from basin centre shales into the 'shoreline' sandstones during shallow burial. However, it should be stressed that these sandstones are only 'shoreline' in the sense of their palaeogeographic location. Most of them are dominated by the same types of predominantly aeolian sedimentary structures as the underlying Slochteren Formation. They are interpreted as the deposits of aeolian dunes (and interdune areas) which formed on the dried-up lake floor, during times of lacustrine regression. Across the study area, the Wustrow Sandstone Member is presently buried to depths of between 4.7 and $4.9 \mathrm{~km}$. To the north of the study area the Rotliegend succession is dominated by fine-grained 
lacustrine and sabkha deposits and contains up to 16 beds of halite which correlate with both the Hannover and Slochteren Formations, and possibly even with parts of the oldest Schneverdingen Formation (Gast, 1991). Rotliegend continental sedimentation ended with the Zechstein marine transgression and the deposition of a thick sequence of marine evaporites (Fig. 2).

\section{SAMPLES AND METHODS}

Samples are described from nine different boreholes (Fig. 1). Most are from the Wustrow Sandstone Member of the Hannover Formation, but in some boreholes just as many samples were examined from the underlying Slochteren and the Schneverdingen Formations. Exact details of depth and location cannot be given for proprietary reasons. The boreholes are identified simply as A through to $I$, and samplès are identified by the borehole letter and a number which indicates relative depth in metres from an unspecified datum. By coincidence, borehole $G$ of this study corresponds to borehole G of Platt (1993, 1994) but none of the other boreholes is equivalent. Samples were collected over depth intervals of between 50 to $250 \mathrm{~m}$, with between 5 to 20 samples per borehole, totalling about 100 samples in all.

For scanning electron microscopy (SEM), 20 selected samples were osmium saturated, gold coated and examined using a Camscan $\mathrm{S} 4$ instrument. For all samples, the $<2 \mu \mathrm{m}$ clay fraction was separated by gravity settling, sedimented onto a glass slide and examined by $\mathrm{X}$-ray diffraction (XRD) in the air-dried state by counting for $1 \mathrm{~s}$ at steps of $0.02^{\circ} 2 \theta$ from 2 to $35^{\circ} 2 \theta$ using $\mathrm{Cu}-\mathrm{K} \alpha$ radiation. From artificial mixtures of pure illite and chlorite separated from Rotliegend samples it was established that the integrated intensity ratio of the illite 002 and chlorite 003 was approximately equal to their weight ratio. Thus the amounts of chlorite and illite in each sample were estimated by measuring the integrated intensities of these two peaks and normalizing to $100 \%$. For selected samples, XRD was also used for semi-quantitative determination of the $\mathrm{Fe} /(\mathrm{Fe}+\mathrm{Mg})$ ratio of the chlorites by measuring the position of the 060 peak in $<2 \mu \mathrm{m}$ samples prepared as random powders. This was only possible for samples rich in chlorite because of overlap of the chlorite 060 with $h k l$ peaks arising from illite in illite-rich samples. The position of the quartz 211 peak was used as an external $d$-spacing standard. Assessment of this method using chlorites of known $\mathrm{Fe} /$ $(\mathrm{Fe}+\mathrm{Mg})$ ratio showed that the following equation from Brindley (1961) gave the most accurate results:

$$
b=9.210 \AA+0.037\left(\mathrm{Fe}^{2+}, \mathrm{Mn}\right)
$$

where $b$ is equal to six times the measured $d$-spacing of the 060 peak. This equation gives the number of heavy atoms per 12 octahedral sites. The $\mathrm{Fe} /(\mathrm{Fe}+\mathrm{Mg})$ ratio was derived from this result by assuming that $(\mathrm{Fe}+\mathrm{Mg})=8.5$ atoms per formula unit. This assumption was based on the $(\mathrm{Fe}+\mathrm{Mg})$ totals of electron microprobe analyses of Rotliegend chlorites from polished thin-sections, examples of which can be found in Hillier (1994). Microprobe data reported in the present paper were obtained with a Cameca SX50 instrument using identical measuring conditions and standards as detailed in Hillier (1994).

Chlorite in samples selected for oxygen and hydrogen stable isotope analysis was separated and purified by a combination of size fractionation and high gradient magnetic separation (HGMS). For each sample, a fraction $<6 \mu \mathrm{m}$ was separated by gravity settling and iron oxides removed by the citrate-bicarbonate-dithionite method (Mehra \& Jackson, 1960). The fraction $<2 \mu \mathrm{m}$ was then removed by repeated timed centrifugation to obtain a $2-6 \mu \mathrm{m}$ fraction for HGMS. This fraction was chosen for HGMS because chlorite was preferentially concentrated in it as a consequence of its grain-size distribution. The HGMS apparatus was similar to that described by Russell et al. (1984). However, the magnetic filter was as big as possible and filled only sparsely (1\%) with \#430 grade stainless steel wool because empirical experience with the technique led to the conclusion that the main limitation to HGMS of clay minerals from sandstones is probably physical trapping of the unwanted particles in the steel wool network. Samples were circulated continuously through the filter in suspension at a concentration of about $200 \mathrm{mg} \mathrm{l}^{-1}$, for a total of 5 minutes. The flow velocity in the filter was set to $10 \mathrm{~cm} \mathrm{sec}^{-1}$, and the magnetic flux density was 0.2 Tesla.

This procedure produced chlorite separates of between 10 to $40 \mathrm{mg}$ to a purity, in most cases, better than $90 \%$. The main contaminant was illite and purity was assessed by a combination of XRD and measurement of the $\mathrm{K}_{2} \mathrm{O}$ content of ten selected separates by electron microprobe analysis. These 
analyses also provided further data on the $\mathrm{Fe} /(\mathrm{Fe}+\mathrm{Mg})$ ratio of the chlorites because this ratio is not measurably altered by the amount of illite contamination present. Furthermore, the $\mathrm{Fe} /(\mathrm{Fe}+\mathrm{Mg})$ ratio of chlorite is qualitatively correlated with the chlorite 001/002 intensity ratio in XRD patterns and values derived from an empirical correlation of this ratio with the values measured on the HGMS separates by microprobe are also reported. Four of the HGMS separates were also examined by transmission electron microscopy (TEM) using a Siemens Elmiskop 102.

The methods used for oxygen and hydrogen isotopic analyses of fine-grained minerals have been published previously (Fallick et al., 1993; Hogg et al., 1993). Briefly, oxygen was liberated from approximately $10 \mathrm{mg}$ samples by overnight reaction at $650^{\circ} \mathrm{C}$ with $\mathrm{ClF}_{3}$ (Borthwick \& Harmon, 1982) in nickel reaction vessels. There was no prefluorination step but the samples had been degassed overnight at $200^{\circ} \mathrm{C}$ in an off-line vacuum system (see Hogg et al., 1993). Released oxygen was purified and reduced to $\mathrm{CO}_{2}$ by platinized graphite (Clayton \& Mayeda, 1963) Overall reaction yields were determined manometrically. The $\delta^{18} \mathrm{O}$ value of $\mathrm{CO}_{2}$ was measured on a VG-SIRA 10 mass spectrometer with a working standard calibrated against international standards; NBS28 quartz gives $\delta^{18} \mathrm{O}=9.6 \%$ relative to SMOW .

Hydrogen was extracted by induction heating under vacuum of a platinum crucible containing the sample (20-40 mg). Water produced during dehydroxylation was converted to $\mathrm{H}_{2}$ over $\mathrm{U}$ at $700^{\circ} \mathrm{C}$ in a multiple pass system (Friedman \& Smith, 1958) and the yield was measured by manometer employing a Toepler pump for $\mathrm{H}_{2}$. The Pt crucible had previously been degassed for at least $3 \mathrm{~h}$ prior to hydrogen extraction. The $\delta \mathrm{D}$ value of $\mathrm{H}_{2}$ was measured on a VG602 mass spectrometer with a working standard calibrated against international water standards; NBS30 biotite gives $\delta \mathrm{D}=-65 \%$ relative to SMOW.

Analytical precision of isotopic analyses is conservatively estimated at $\pm 0.5 \%$ for $\delta^{18} \mathrm{O}$ and better than $\pm 5 \%$ for $\delta \mathrm{D}$.

\section{RESULTS}

\section{Chlorite abundance and distribution}

Examination of the $<2 \mu \mathrm{m}$ fraction of all samples by XRD showed that chlorite is present in almost all of them and in all formations, but in amounts which vary widely from trace quantities up to $\sim 90 \mathrm{wt} \%$. Examples of these analyses for samples which were subsequently analysed for oxygen stable isotope ratios are given in Table 1 . In general, chlorite tends to be most abundant, typically $80 \%$ of the $<2 \mu \mathrm{m}$ fraction, in the Wustrow Sandstone Member of the Hannover Formation of the most northerly wells A, B, D, G and $F$, decreasing in abundance in a southerly direction to values of around $20 \%$ in wells $\mathrm{E}$ and $\mathrm{I}$. In all wells, chlorite also tends to decrease in abundance downhole into the Slochteren and Schneverdingen Formations (Table 1). Although these trends are only general, and there are local variations, such as zones where chlorite is abundant (up to $80 \%$ ) in the Slochteren and Schneverdingen sandstones, the overall distribution of chlorite is wedge-like, thinning towards the south.

\section{Chlorite chemical composition}

The results of both electron microprobe and XRD analyses of the Rotliegend pore-lining chlorites show that most of them are $\mathrm{Mg}$-rich, as was reported previously (Platt, 1993; Hillier, 1994). However, the much more extensive data of the present investigation also revealed that in some cases the Rotliegend pore-lining chlorites are $\mathrm{Fe}$ rich. Specifically, the $\mathrm{Fe} /(\mathrm{Fe}+\mathrm{Mg})$ ratio varies considerably from 0.21 to 0.68 , but of even more significance is the observation that this variation is systematic, both across the study area and downhole.

Regional variation of the $\mathrm{Fe} /(\mathrm{Fe}+\mathrm{Mg})$ ratio is shown in Fig. 3 where all available data for the Wustrow Sandstone Member of the Hannover Formation, from each of the study boreholes, are plotted as a map. Clearly, in the north of the study area, in the direction of the basin centre, the porelining chlorites are more $\mathrm{Mg}$-rich, and in the south of the area, towards the basin margin, they become progressively more Fe-rich. Most of these data are from samples which were also analysed for oxygen stable isotope ratios and are reproduced in Table 1. On average the lateral gradient in $\mathrm{Fe} /(\mathrm{Fe}+\mathrm{Mg})$ of chlorites in the Wustrow Sandstone Member across the study area is of the order of $\sim 0.03 \mathrm{~km}^{-1}$ (Fig. 3). The data also illustrate the reasonable consistency of the results of all three quantitative methods of determining $\mathrm{Fe} /(\mathrm{Fe}+\mathrm{Mg})$, i.e. electron microprobe analysis of the chlorites both in thin- 


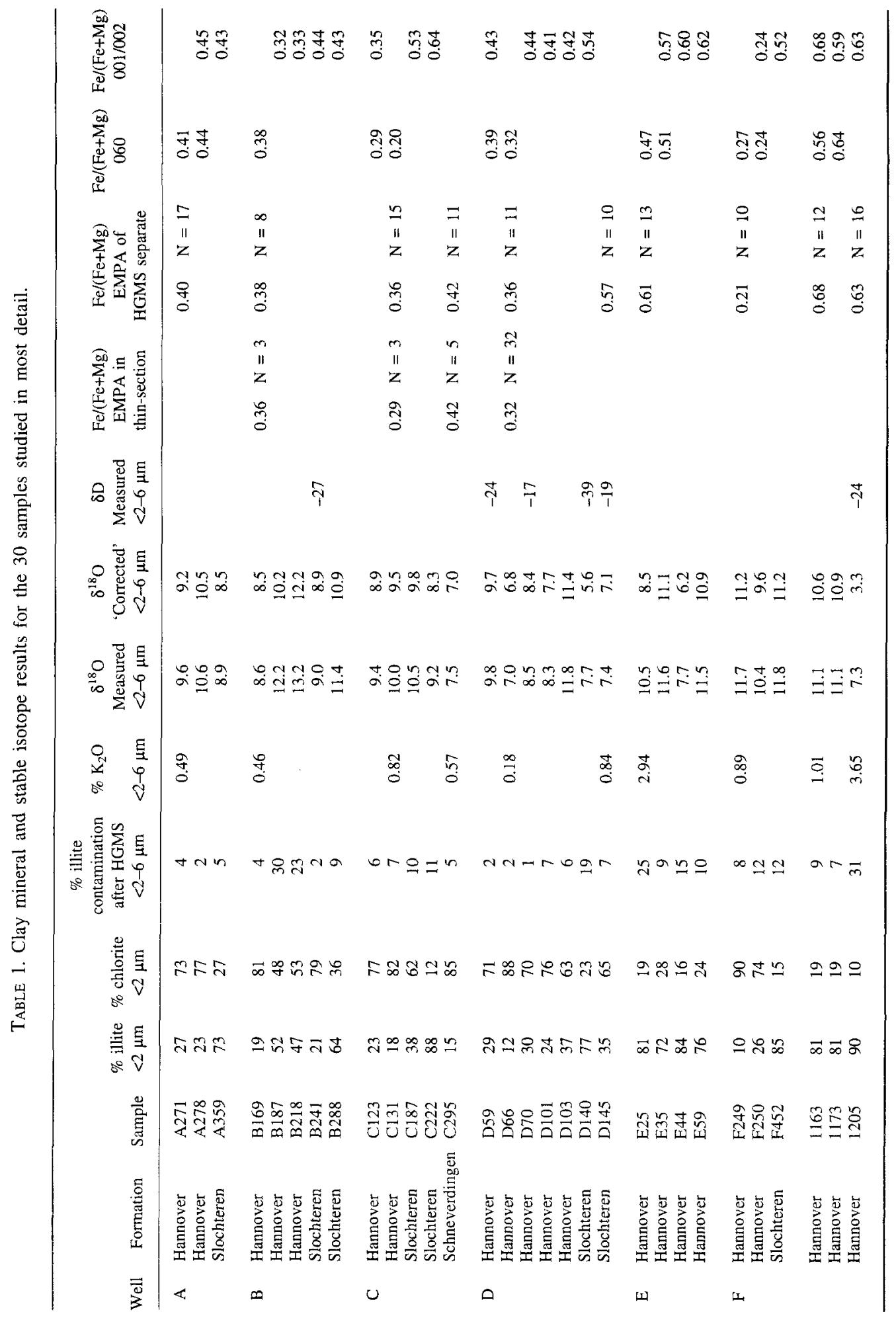




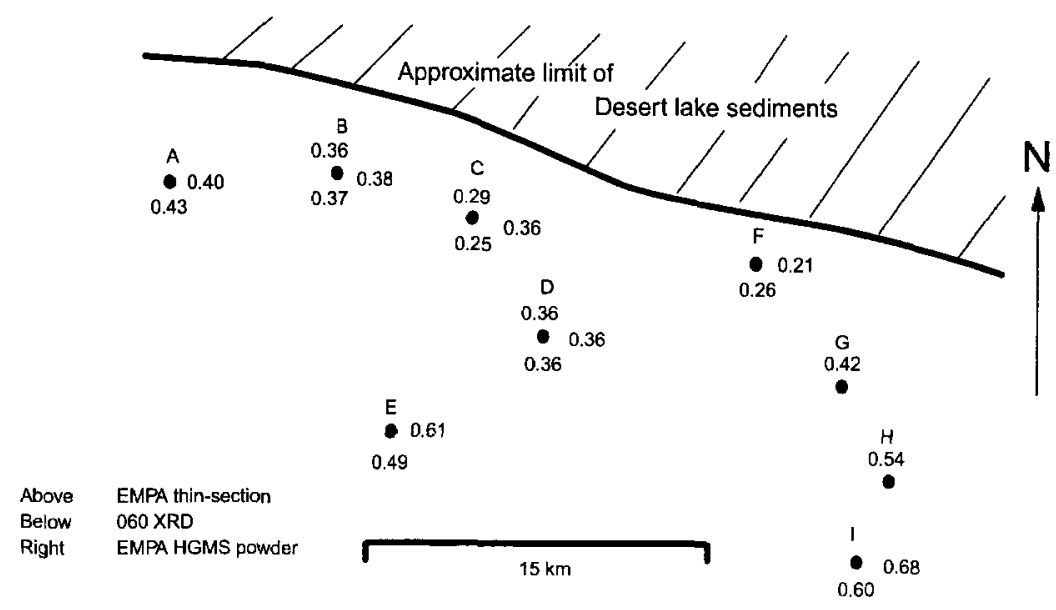

FIG. 3. Map of variation in chlorite chemistry $(\mathrm{Fe} /(\mathrm{Fe}+\mathrm{Mg})$ across the study area for samples from the Wustrow Sandstone. The map is based on the results of three different methods of determining the $\mathrm{Fe} /(\mathrm{Fe}+\mathrm{Mg}) \mathrm{ratio}$ : electron microprobe analyses of the chlorites in polished thin-sections; the position of the 060 peak in XRD patterns of random powders, and electron microprobe analyses of the chlorites separated from the $2-6 \mu \mathrm{m}$ fractions by HGMS. Electron microprobe data are based on 143 individual analyses, and XRD data on 14 individual analyses most of which were made on samples also analysed for stable isotopes as reported in Table 1. Also shown is the approximate limit of 'desert lake sediments' for the study area after work by Gast (1991).

section and as powders separated by HGMS, and XRD analysis of the position of the 060 peak. Examples of XRD patterns of pore-lining chlorites which span most of the observed compositional range are illustrated in Fig. 4. These particular examples have been purified by HGMS for measurement of stable isotope ratios and the $\mathrm{Fe} /(\mathrm{Fe}+\mathrm{Mg})$ ratios on the figure are those determined by direct microprobe analysis of the purified chlorite powders. Qualitatively, however, the compositional variation is readily apparent from the changing ratios of the odd- and even-order peaks such as the 001/002 ratio, which in these three examples varies from 0.48 to 0.18 . Qualitative estimates of the $\mathrm{Fe} /(\mathrm{Fe}+\mathrm{Mg})$ based on the $001 / 002$ ratio for other chlorites not analysed by microprobe are given in Table 1. Random powder XRD patterns for chlorites covering the range of $\mathrm{Fe} /(\mathrm{Fe}+\mathrm{Mg})$ are consistently of the $I l b$ polytype, an example of which is given by Hillier (1994).

Downhole trends in chlorite composition into the formations underlying the Wustrow Sandstone are somewhat more variable. Nevertheless, to some extent they are also systematic in that the $\mathrm{Fe} /(\mathrm{Fe}+\mathrm{Mg})$ ratio either increases with depth into the Slochteren and Schneverdingen Formations or is approximately constant with depth (Table 1). Systematic decreases in $\mathrm{Fe} /(\mathrm{Fe}+\mathrm{Mg})$ with depth were never observed. Borehole D and borehole A provide examples of these two situations as illustrated by the XRD patterns in Fig. 5 and the data in Table 1. For borehole $A$ the chlorite in sample A271 from the Wustrow Sandstone has an $\mathrm{Fe} /(\mathrm{Fe}+\mathrm{Mg})$ ratio of 0.40 , similar to the value of 0.38 from sample $\mathrm{A} 376$, some $100 \mathrm{~m}$ deeper in the Slochteren, and all the intervening samples have similar compositions. In contrast, in borehole D, the chlorite in sample D66 from the Wustrow Sandstone has an $\mathrm{Fe} /(\mathrm{Fe}+\mathrm{Mg})$ ratio of 0.36 compared to 0.57 for sample D145, some $80 \mathrm{~m}$ deeper in the Slochteren Formation. Intervening samples in well $D$ show that this increase in $\mathrm{Fe} /(\mathrm{Fe}+\mathrm{Mg})$ with depth is more or less progressive (Table 1).

In general, it is also apparent that trends in chlorite composition are correlated with trends in chlorite distribution and abundance. Specifically, where chlorites are Fe-rich they tend to be less abundant relative to illite and cover framework grains less continuously than their $\mathrm{Mg}$-rich counterparts (Fig. 6, Table 1). Interestingly, changes in chlorite composition are also consistently correlated with changes in their morphology as shown in Fig. 6. Typically, the more Fe-rich chlorites such as that from sample D145 tend to have larger, thicker, and more euhedral crystals compared to the more 


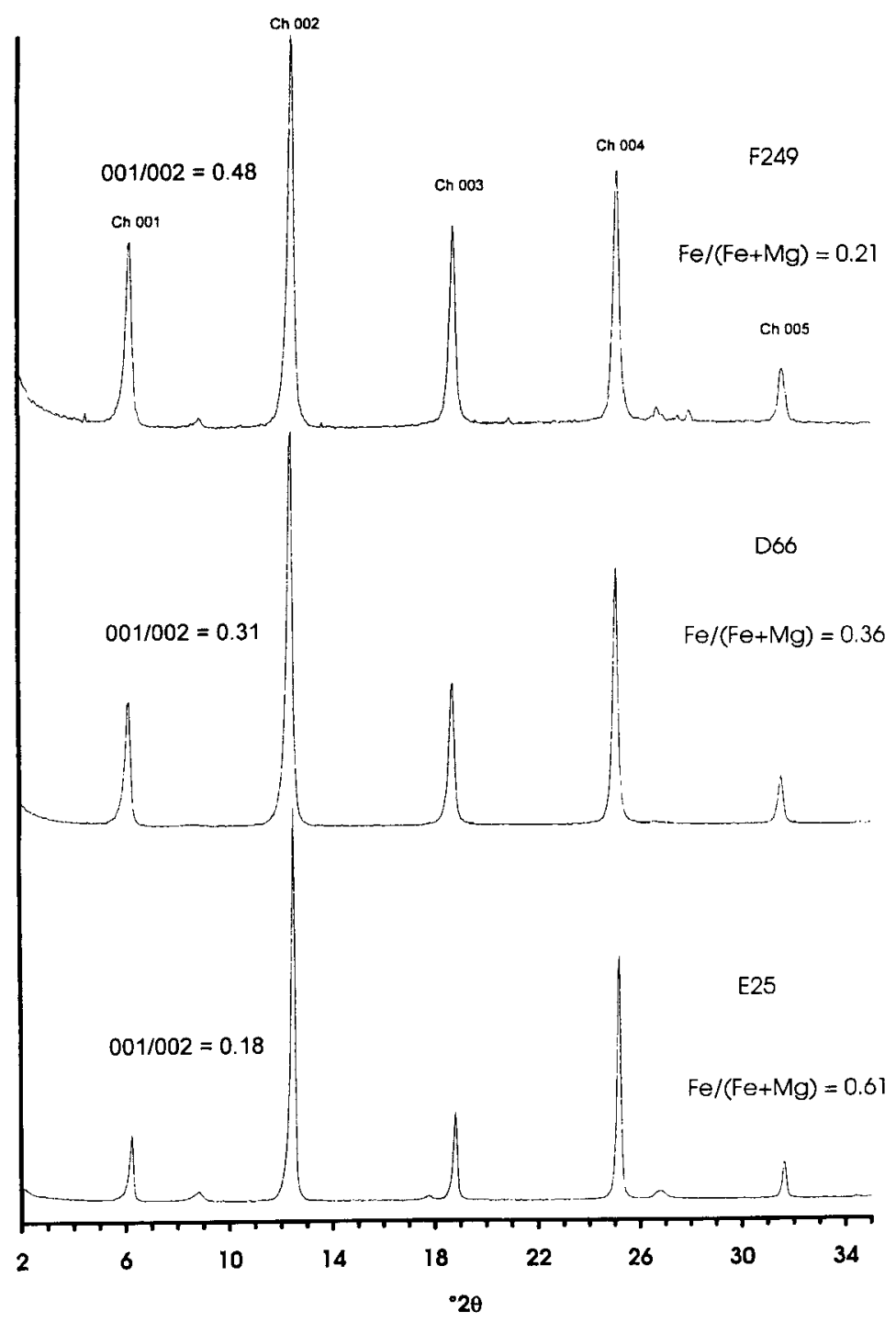

FIG. 4. XRD patterns from oriented aggregates of three different chlorite samples from boreholes $\mathrm{D}, \mathrm{E}$ and $\mathrm{F}$, after purification by $\mathrm{HGMS}$. The $\mathrm{Fe} /(\mathrm{Fe}+\mathrm{Mg})$ ratio of these chlorites, as determined by electron microprobe analysis of the HGMS purified sample, ranges from 0.21 to 0.61 . $\mathrm{Cu}-\mathrm{K} \alpha$ radiation.

Mg-rich ones such as that from sample D66 (Fig. 6). However, in both cases there are numerous face-to-face contacts and an overall boxwork arrangement. In TEM images (Fig. 7) most of the chlorite crystals appear to be coherent aggregates similar to the quasicrystals of illite-smectite described by Whitney \& Velde (1993). In the Rotliegend samples it seems probable that these quasicrystals correspond to the face-to-face aggre- gates seen in the SEM images (Fig. 6). The morphological differences between the $\mathrm{Fe}$ - and $\mathrm{Mg}$-rich chlorites observed by SEM were not apparent under the TEM, except perhaps that the Fe-rich examples did appear to contain more thicker crystals than the Mg-rich ones. The TEM images illustrated in Fig. 7 are taken from those samples for which XRD patterns are shown in Fig. 4 with values of $\mathrm{Fe} /(\mathrm{Fe}+\mathrm{Mg})$ ranging from 0.21 to 0.61 . 

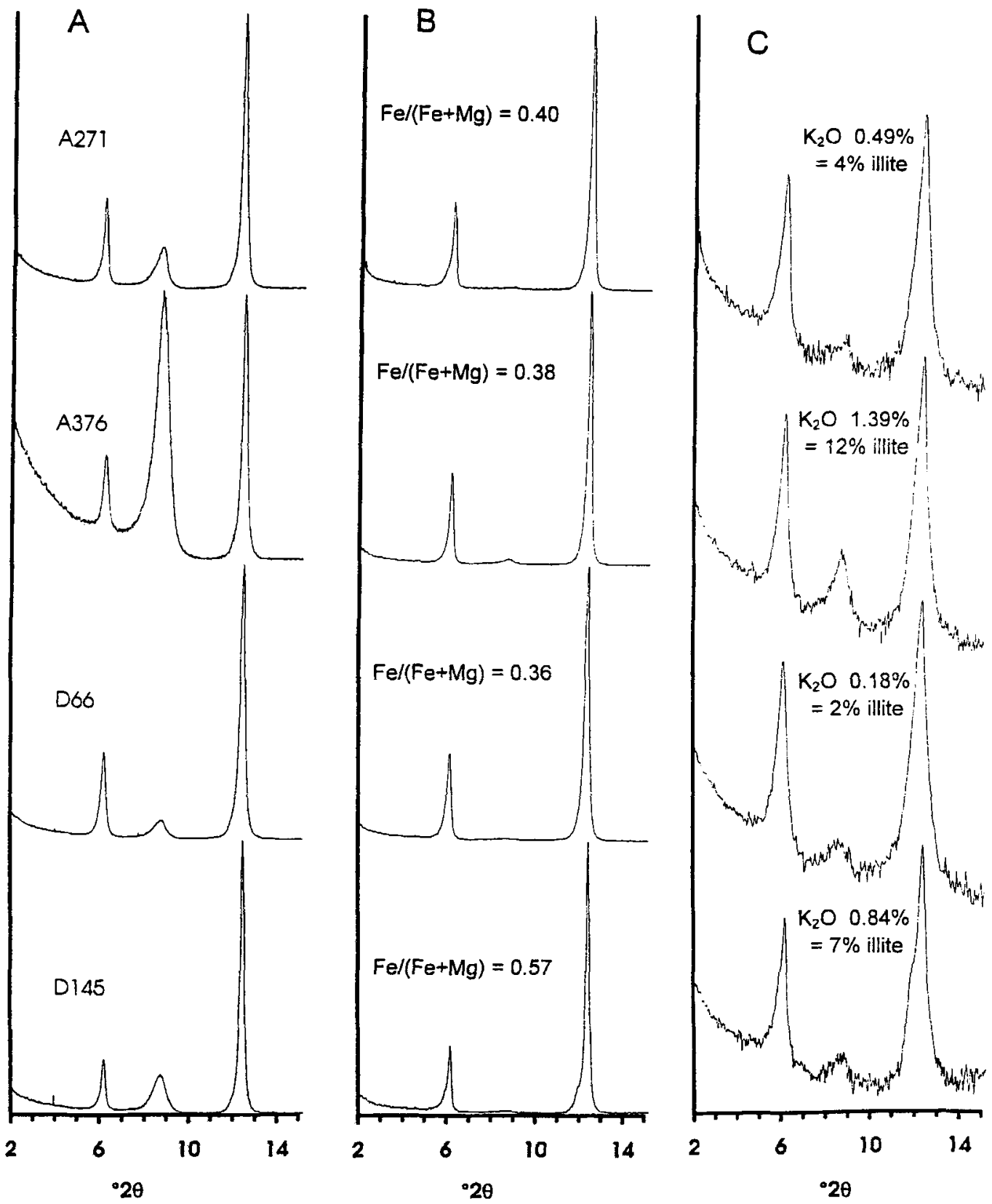

FIG. 5. XRD patterns of oriented aggregates before (A) and after (B \& C) HGMS. X-ray intensity of the patterns in $A$ and $B$ is on a linear scale, whereas $C$ shows the same XRD patterns as B but with intensity on a log scale. The log scale patterns highlight the fact that some illite contamination is still present in all samples, as revealed by the 001 illite peak. Also shown are the corresponding $\mathrm{Fe} /(\mathrm{Fe}+\mathrm{Mg})$ ratios of the purified chlorites shown in $\mathrm{B}$ and $\mathrm{C}$ and their $\mathrm{K}_{2} \mathrm{O}$ contents as measured by electron microprobe. The estimated percentage of illite contamination is based on the measured $\mathrm{K}_{2} \mathrm{O}$ content. Note the inflections evident in the chlorite peaks for sample D145 in B and C are due to the use of an old X-ray tube badly contaminated with tungsten during measurement of this trace. $\mathrm{Cu}-K \alpha$ radiation. 

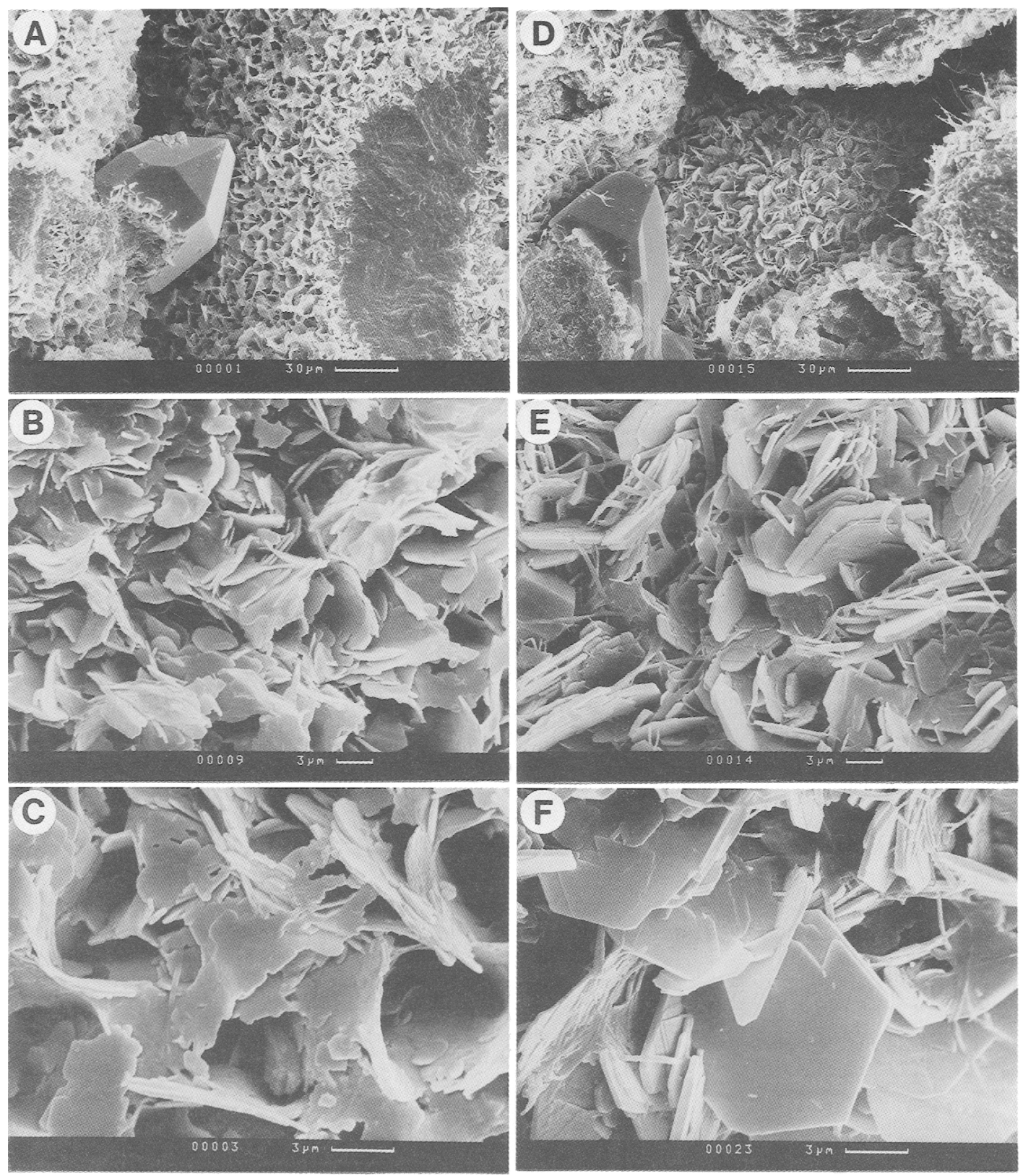

Fig. 6. SEM micrographs of a Mg-rich (A,B,C) (Sample D66) and an Fe-rich (D,E,F) (Sample D145) chlorite from borehole D. Both samples show a boxwork or honeycomb arrangement of crystals over the surface of the framework grains with many face-to-face contacts between crystals. Note the Fe-rich chlorite has more illite associated with it. The XRD patterns of these same two samples are shown in Fig. 5. 

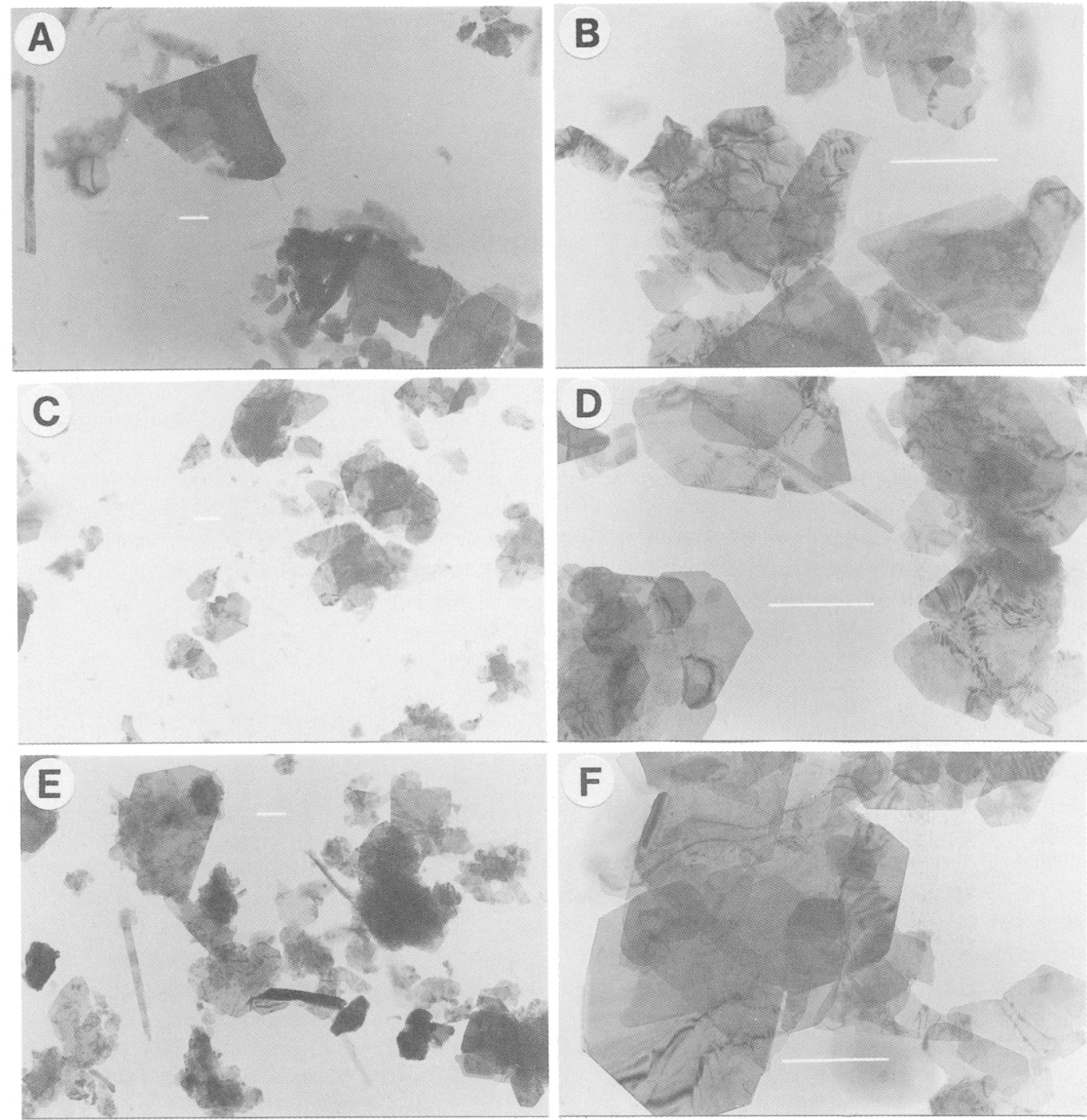

FIG. 7. TEM images of chlorites separated by HGMS. Most of the chlorite crystals are arranged into coherent aggregates or quasicrystals. The presence of laths of illite in the images also confirm that not all illite has been removed from the samples by HGMS. A and B are from sample E25, C and D are from sample D66, and E and F are from sample F249. Scale bars are all $1 \mu \mathrm{m}$ in length.

One further notable feature concerning the composition of the Rotliegend pore-lining chlorites is that they all appear to be relatively rich in $\mathrm{Mn}$. Contents of $\mathrm{MnO}$ up to $0.5 \mathrm{wt} \%$ are common, and in comparison to diagenetic chlorites generally (Hillier and Velde, 1991; Hillier, 1994), such values must be regarded as relatively high.

\section{Stable isotopes}

Oxygen stable isotope ratios were measured successfully on 30 chlorites purified by HGMS from seven of the nine boreholes and the data are shown as a map in Fig. 8 and given in Table 1. The results show a range of $\delta^{18} \mathrm{O}$ from +7 to $+13.2 \%$ 


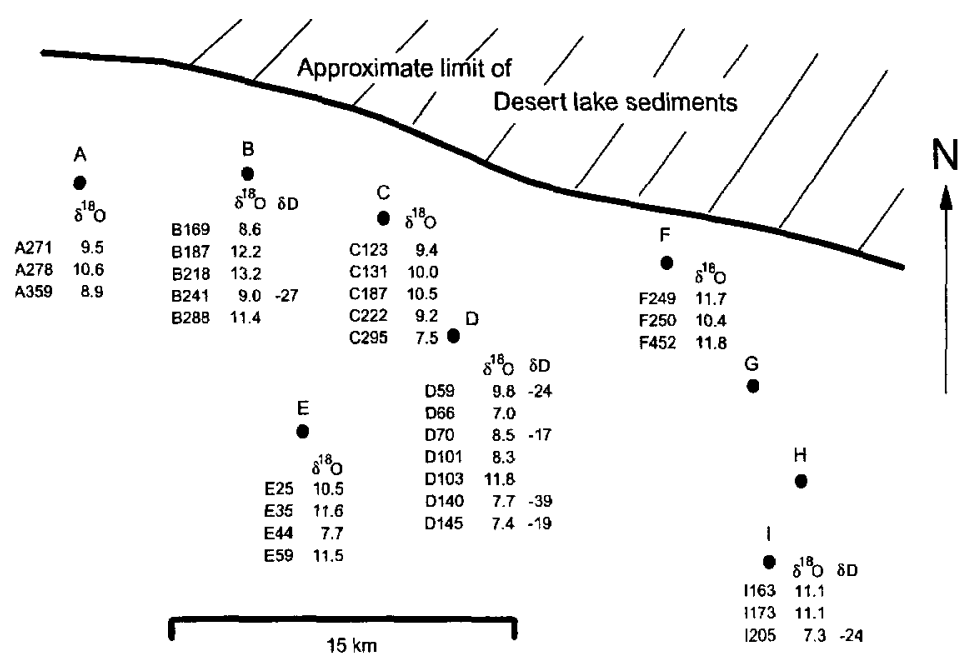

FIG. 8. Map of oxygen and hydrogen stable isotope data for chlorites separated by HGMS. Note sample numbers indicate relative depth of different samples in metres. Also shown is the approximate limit of 'desert lake sediments' for the study area after work by Gast (1991).

(SMOW), with no evidence of any regional or depth related trends (Fig. 8). As illustrated in Figs. 4,5 and 7 , all of the samples still contain some illite contamination, so an attempt was made to correct the isotope ratios for this to see if contamination might be obscuring any trends. The amount of illite contamination was determined by a combination of XRD and measurement of the $\mathrm{K}_{2} \mathrm{O}$ content of selected separates, examples of which are given in Fig. 5. Illite was assumed to have an oxygen isotope ratio of $+17 \%$ (SMOW), based on data for Rotliegend illite from the study area given by Platt (1993). The results of this exercise are shown in Fig. 9 as histograms of the isotope ratios before and after correction and the data are given in Table 1. Evidently, for the vast majority of samples this attempt to correct for the small amounts of illite present makes little difference to the measured isotope ratios (for most no more than $0.5 \%$ ), so that there are still no obvious trends in the data with respect to location, depth or chlorite chemistry. The only notable point concerning contamination is that two of the samples (B187 and B218) which were more contaminated than most, with between 20 to $30 \%$ illite, had the highest $\delta^{18} \mathrm{O}$ ratios of 12.2 and $13.2 \%$ of all the data suggesting that they were indeed higher than most others because of the illite contamination present. However, another sample (1205) which was similarly contaminated has a measured $\delta^{18} \mathrm{O}$ value of $7.3 \%$. For six samples

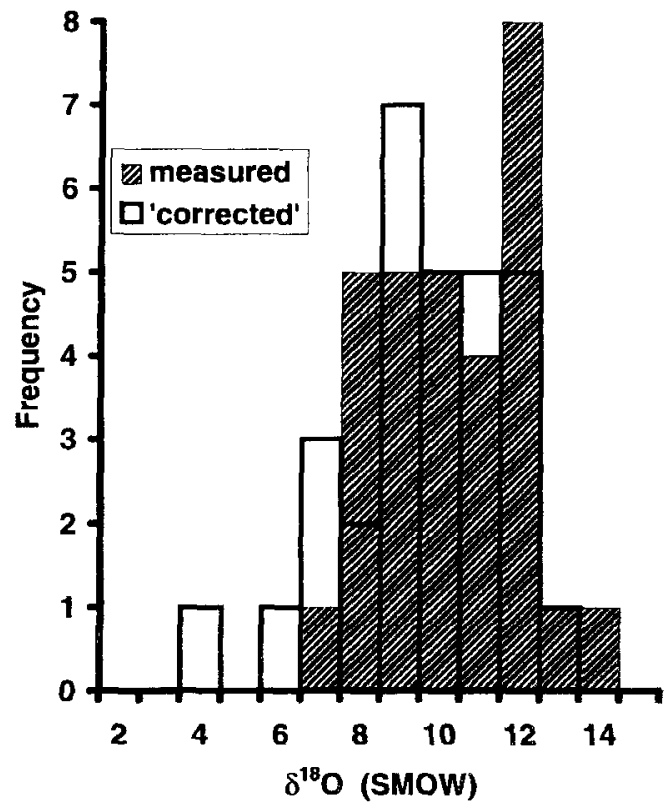

FIG. 9. Histogram of oxygen isotope ratios for chlorite separates as measured and as 'corrected' by attempting to account for the affect of small amounts of illite contamination. Histograms include only data for the $2-6 \mu \mathrm{m}$ size-fractions. 
there was also enough material to determine $\delta \mathrm{D}$, which ranged between -39 and $-17 \%$ (Fig. 8).

In addition to measuring the oxygen isotope ratio on the 2-6 $\mu \mathrm{m}$ fraction, for two samples an attempt was made to separate chlorite by HGMS from five different size-fractions, namely $<0.2, \quad 0.2-0.6$, $0.6-2,2-6$, and $6-20 \mu \mathrm{m}$. Eventually, separation and analysis were made successfully on seven out of the ten fractions and the results are illustrated in Fig. 10 and Table 2. For both samples the coarser fractions were the least contaminated with illite and the finest size-fractions the most contaminated, particularly the $<0.2 \mu \mathrm{m}$ size-fraction of sample D145. For sample D59, there is a clear trend for $\delta^{18} \mathrm{O}$ to increase with increasing size-fraction, a trend which is not significantly altered by the attempt to correct for illite contamination. However, for sample D145 there is no apparent trend and the measured value for the $<0.2 \mu \mathrm{m}$ fraction is clearly unreliable. Taken as a whole, the results from the different size-fractions of both samples span almost the same range of $\delta^{18} \mathrm{O}$ as the entire data set for the chlorites from the $2-6 \mu \mathrm{m}$ size-fractions.

\section{DISCUSSION}

\section{Origin of pore-lining chlorite}

In previous work on the Rotliegend of northern Germany, Gaupp et al. (1993) and Platt (1993) concluded that pore-lining chlorite was one of the very first diagenetic minerals to form in these rocks, during the earliest stages of burial. However, as argued subsequently (Hillier, 1994) it is unlikely that chlorite was the original pore-lining clay mineral and it is more likely that there has been a succession of minerals beginning with a trioctahedral smectite followed by corrensite, and finally by chlorite. This suggestion was based on several observations including: (1) chlorite does not form at near-surface temperatures (Hillier, 1993); (2) the honeycomb or boxwork texture of the Rotliegend chlorites, which is reminiscent of, and possibly inherited from, a swelling clay precursor; and (3) the Rotliegend chlorites are all of the $I l b$ polytype, which is generally considered to be a high temperature $\left(>150^{\circ} \mathrm{C}\right)$ form (Bailey, 1988; Walker, 1993). The succession from original smectite eventually to chlorite is considered to be the result of temperature increase during burial.

In such a sequence, specific temperatures for the transition and reaction from one phase to another are difficult to assess. However, based on data for diagenetic alteration of trioctahedral smectite in other diagenetic and hydrothermal sequences, as reviewed by Hillier (1993), a temperature near to $100^{\circ} \mathrm{C}$ is probable for a smectite to corrensite transition. Data on the temperature over which corrensite reacts to chlorite are less abundant. Furthermore, in some systems, corrensite may persist to temperatures as high as $280^{\circ} \mathrm{C}$ (Hillier, 1993), so that temperature alone is clearly not the

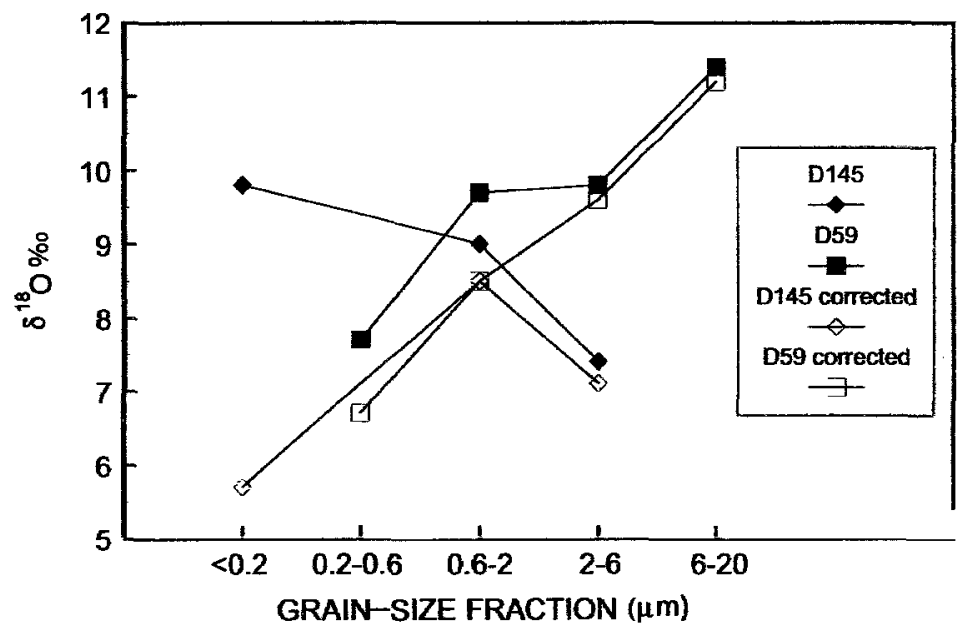

FIG. 10. Variation in oxygen stable isotope ratios of chlorite from different size-fractions of two samples from borehole $\mathrm{D}$. Solid symbols show measured values and open symbols show values after attempt to correct for illite contamination. 
TABLE 2. Variation of chlorite oxygen isotope ratio with grain-size.

\begin{tabular}{lcccc}
\hline Sample & $\begin{array}{c}\text { Size-fraction } \\
(\mu \mathrm{m})\end{array}$ & $\begin{array}{c}\delta^{18} \mathrm{O} \\
\text { measured }\end{array}$ & $\begin{array}{c}\% \text { illite } \\
\text { contamination }\end{array}$ & $\begin{array}{c}\delta^{18} \mathrm{O} \\
\text { 'corrected' }\end{array}$ \\
\hline D59 & $6-20$ & 11.4 & 3 & 11.2 \\
D59 & $2-6$ & 9.8 & 4 & 9.6 \\
D59 & $0.6-2$ & 9.7 & 14 & 8.5 \\
D59 & $0.2-0.6$ & 7.7 & 10 & 6.7 \\
& & & & \\
D145 & $2-6$ & 7.4 & 4 & 7.1 \\
D145 & $0.6-2$ & 9 & 7 & 8.5 \\
D145 & $<0.2$ & 9.8 & 38 & 5.7 \\
& & & & \\
\hline
\end{tabular}

only factor involved. Nonetheless, the fact that there is no longer any trace of corrensite in the Rotliegend sandstones of the study area suggests that the higher part of the range of $150-200^{\circ} \mathrm{C}$ for chlorite formation may be most reasonable.

Gaupp et al. (1993) noted that the most abundant pore-lining chlorite was distributed in the form of a belt parallel to the Rotliegend lake shoreline and especially concentrated in the $\mathrm{N}-\mathrm{S}$ trending graben which ran across it. Furthermore, Platt (1993) pointed out that the occurrence of pore-lining chlorite bears no relationship to the presence of any detrital volcanic material that may or may not be present. Based on these observations they suggested that chlorite formation may have been related to the migration of alkaline compactional waters from the basin centre sequence of shales and evaporites into the sandstones during shallow burial.

The chemical zonation of the Rotliegend porelining chlorites across the study area documented for the first time in the present investigation (Fig. 3) provides compelling support for such an origin. Towards the basin centre the chlorites are abundant and $\mathrm{Mg}$-rich, and with increasing distance away from the lake basin they become more Fe-rich and less abundant. Such a chemical zonation and distribution is exactly what might be expected if chlorite formation, or more likely its trioctahedral smectite precursor, occurred as a result of the migration of $\mathrm{Mg}$-rich fluids up dip into the sandstones from the basin centre succession of evaporites and shales. Furthermore, it may also explain the observed depth related trends in chemistry whereby the chlorites tend to become more $\mathrm{Fe}$-rich or remain fairly constant in composi- tion with depth. In the study area, basin centre lacustrine sedimentation progressively expanded in a southerly direction through Rotliegend times (Gast, 1991) so that the depth trends may be interpreted as a succession of superimposed lateral trends related to varying distances of lateral fluid migration from basin centre shales. In other words, the trends in chlorite composition with depth may reflect the connectivity to, and distance of the sandstones from, laterally equivalent shale sequences, i.e. the source of the $\mathrm{Mg}$-rich fluids (Fig. 11).

Unlike previous investigations (Platt, 1993; Gaupp et al., 1993) which have emphasized the association of pore-lining chlorite with 'shoreline' sands, the present study demonstrates a wider distribution of pore-lining chlorite throughout the Rotliegend succession of the study area, as well as a wider range of pore-lining chlorite composition. However, there is no doubt that the pore-lining chlorite tends to be most abundant in aeolian sandstones that interfinger with the sabkha and lacustrine shales (Platt, 1993; Gaupp et al., 1993). Indeed, this association implies that these sandstones were deposited in a 'shoreline location' peripheral to the Rotliegend lake. Furthermore, although the best developed pore-lining chlorites are Mg-rich, where they become less abundant they become Fe-rich. This demonstration of a range of composition is an important point because in previous work (Platt, 1993; Gaupp et al., 1993) chlorites in the Rotliegend of northern Germany have been divided into $\mathrm{Mg}$-rich pore-lining chlorites known as 'radial' or 'Chlorite I' and Fe-rich chlorites known as 'late' or 'Chlorite II'. The latter frequently occur as pore fillings or grain 


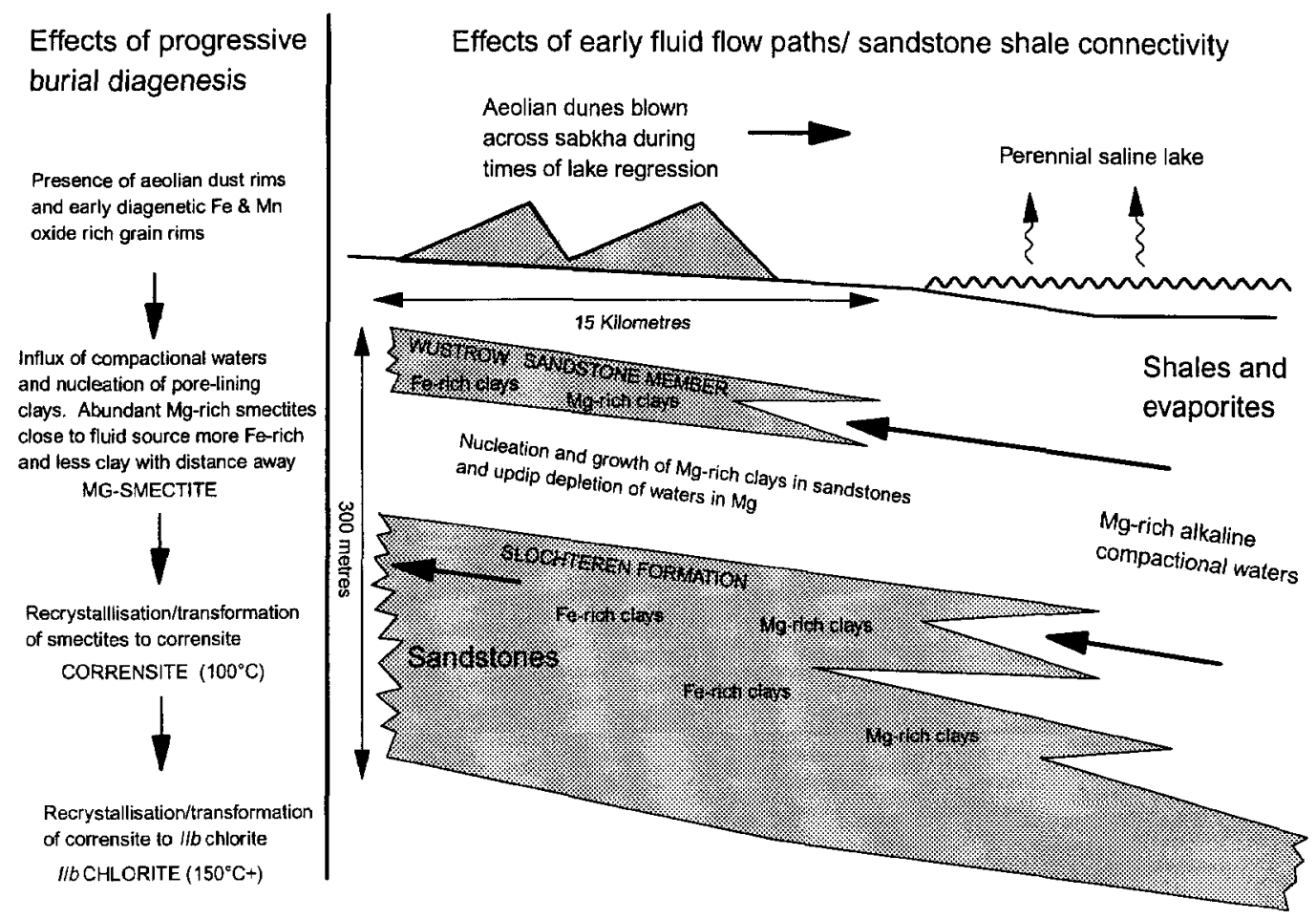

FIG. 11. Model of the origin and evolution of pore-lining chlorite in the Rotliegend of Northern Germany in terms of the source and pathways of Mg-rich pore-waters during shallow burial, and the probable evolution of an early formed Mg-rich trioctahedral pore-lining smectite to chlorite as a result of deep burial. Note different horizontal and vertical scales.

replacements, formed at a later time than 'Chlorite 1 ' and are especially common in the vicinity of faults. Indeed, they tend to be very Fe-rich with $\mathrm{Fe} /(\mathrm{Fe}+\mathrm{Mg})$ ratios of $0.6-0.85$ (Platt, 1993) and so are quite distinct from the pore-lining examples described in the present investigation which are end-members of a mostly $\mathrm{Mg}$-rich set.

Concerning the source of the $\mathrm{Mg}$, in the basin centre succession up to 15 beds of halite were deposited during times of regression and evaporitic concentration of the lake waters (Glennie, 1990; Gast, 1991). At such times concentrations of $\mathrm{Mg}$ in the pore-waters of the associated sabkha and lacustrine sediments must have been elevated. Thus, migration of such $\mathrm{Mg}$-rich pore-waters into the aeolian sandstones during burial may have occurred simply as a result of early compaction. Other major elements such as Fe may have been supplied by reaction of such fluids with early formed Fe-rich oxy-hydroxide coatings on the sand grains. Furthermore, this is suggested because such coatings can also be invoked as the source of the unusual contents of $\mathrm{Mn}$ in the chlorites. Interestingly, carbonates shown by Platt (1993) to have formed during early diagenesis are also relatively rich in $\mathrm{Mn}$. Additionally, aeolian sandstones frequently exhibit the presence of thin clay coats which may form directly by processes associated with the infiltration of 'dust' or may be inherited from processes which affect the grains during transport across clay-rich sabkha surfaces (Orhan, 1992; Wilson, 1992; Winspear \& Pye, 1995). Such coatings were probably present on the Rotliegend sand grains (e.g. Gaupp et al., 1993) and will probably have served as templates promoting the nucleation and growth of the earliest pore-lining authigenic clay minerals during burial. Subsequent exposure of such coatings to $\mathrm{Mg}$-rich fluids at near- 
surface temperatures would have promoted the formation of a trioctahedral smectite, whereas in areas unexposed to $\mathrm{Mg}$-rich fluids the growth of dioctahedral smectite would be expected. Indeed, generally in the more extensive Rotliegend succession not affected by $\mathrm{Mg}$-rich pore waters from basin centre shales, the occurrence and evolution of porelining dioctahedral clay minerals to various forms of illite was probably the normal pattern of clay mineral burial diagenesis.

The main features of this model for the origin of Rotliegend pore-lining chlorite in the study area, both in terms of the source and pathways of early fluids and of the affect of burial diagenesis, are summarized in Fig. 11. Analogous pore-lining chlorites have been described from the Jurassic aeolian sandstones of the Norphlet Formation from the US Gulf Coast (Dixon et al., 1989; Kugler \& McHugh, 1990). We are not aware of any information on any systematic variations in the chemistry of Norphlet pore-lining chlorite, but overall its similar $\mathrm{Mg}$-rich chemistry, IIb structural type, and boxwork arrangement suggest that it may have a very similar origin to the pore-lining chlorite in the Rotliegend of northern Germany.

\section{Interpretation of stable isotope data}

The interpretation of the chlorite oxygen isotope data requires the choice of a chlorite-water fractionation equation, data on which were summarized by Savin \& Lee (1988). For temperatures $<150^{\circ} \mathrm{C}$, Savin \& Lee (1988) suggest the use of equations calculated by their 'empirical bond-type approach'. However, rather than use the equations of Savin \& Lee (1988), new ones were calculated for chlorite compositions that more closely resemble the natural trioctahedral chlorites examined in this study. The assumptions and conventions used in these calculations are discussed by Savin \& Lee (1988). Notably, all divalent cations are assumed to have the same fractionations, so that no account is yet taken of any affect that the important $\mathrm{FeMg}_{-1}$ substitution in chlorite may have on oxygen fractionation. However, other compositional variation due to substitutions which are coupled/correlated with $\mathrm{FeMg}_{-1}$ can be accounted for. Generally, Mg-rich chlorites are richer in $\mathrm{Si}$, poorer in $\mathrm{Al}$, and have higher divalent cation totals than Fe-rich chlorites (Hillier \& Velde, 1991). Ignoring octahedral vacancies, and assuming an equal distribution of $\mathrm{Al}$ amongst octahedral sheets, chlorite compositions ranging from $\left(M_{4} \mathrm{Al}_{2}(\mathrm{OH})_{12}\right)\left(M_{6} \mathrm{Al}_{2} \mathrm{Si}_{6} \mathrm{O}_{20}(\mathrm{OH})_{4}\right)$ to $\left(M_{3} \mathrm{Al}_{3}(\mathrm{OH})_{12}\right)\left(M_{6} \mathrm{Al}_{3} \mathrm{Si}_{5} \mathrm{O}_{20}(\mathrm{OH})_{4}\right)$ essentially span the entire compositional range of 'common' trioctahedral chlorites from both low- and hightemperature natural environments (Hillier \& Velde, 1991). Using these 'Mg-rich' and 'Fe-rich' compositions, the following chlorite water fractionation equations were calculated:

Mg-rich chlorite:

$$
\begin{gathered}
1000 \ln \alpha_{\text {chlorite-water }}^{\text {Ox }}=4.713\left(10^{3}\right) T^{-1}+3.082\left(10^{6}\right) T^{-2} \\
-0.703\left(10^{9}\right) T^{-3}+0.063\left(10^{12}\right) T^{-4}-14.66
\end{gathered}
$$

Fe-rich chlorite:

$1000 \ln \alpha_{\text {chlorite-water }}^{\text {Ox }}=4.478\left(10^{3}\right) T^{-1}+3.103\left(10^{6}\right) T^{-2}$ $-0.703\left(10^{9}\right) T^{-3}+0.063\left(10^{12}\right) T^{4}-14.08$

The 'Mg-rich' composition used to calculate eqn. 1 is the most appropriate to the compositions of Rotliegend chlorites determined by microprobe analysis, but is in fact almost identical to eqn. 2 derived from the 'Fe-rich' composition. Thus, using the 'empirical bond-type approach', as it stands, together with the assumptions on chlorite structure stated above, there is no suggestion of any significant differences in chlorite water fraction factors related to compositional variation, at least amongst what might be called 'common' types of trioctahedral chlorite.

The calculated equations given by Savin \& Lee (1988) show more differences amongst various chlorites because they are calculated for examples of somewhat unusual composition. Specifically, they include one with a di-trioctahedral structure (their equation d) and one with octahedral $\mathrm{Al}$ concentrated in the octahedral sheet of the 2:1 layer (their equation $c$ ) rather than in the interlayer hydroxide sheet where it is more likely to be located (Bailey, 1988). Of the three equations of Savin \& Lee (1988), e is the most appropriate for 'common' types of trioctahedral chlorites, and is the most similar to those calculated in the present study. For temperatures $>150^{\circ} \mathrm{C}$, Savin \& Lee (1988) suggested that most confidence be placed in the equation given by Cole (1985), based on hydrothermal synthesis experiments.

As described above, chlorite formation is thought to have occurred via a sequence of precursor minerals, the stage of actual chlorite formation probably not beginning until temperatures of between 150 to $200^{\circ} \mathrm{C}$ were attained. At such temperatures the chlorite-water fractionation 
equations shown in Fig. 12 both indicate chlorite formation from waters with positive $\delta^{18} \mathrm{O}$ values. Both eqn. 1 of the present study, and that of Cole (1985) indicate similar compositions ranging from about +2 to $+6 \%$ for the mean measured chlorite value of $9.8 \%$ (SMOW) and from 0 to $+8 \%$ (SMOW) if the entire set of measured chlorite values is considered. Notably, these are comparable to the waters with compositions of $1-6 \%$ (SMOW) which according to Platt $(1993,1994)$ were present during the growth of carbonates, and illites at temperatures of 60 to $115^{\circ} \mathrm{C}$.

The chlorite hydrogen isotope data are more difficult to interpret because of even greater uncertainty concerning fractionation. Nevertheless, some interpretation can be based on the data for the chlorite-water hydrogen isotope fractionation summarized by Savin \& Lee (1988). At the likely temperatures for chlorite formation of $150-200^{\circ} \mathrm{C}$, the average $\delta \mathrm{D}$ of $-25 \%$ suggests the presence of waters with $\delta \mathrm{D}$ of -5 to $+5 \%$. More generally, estimates of chlorite-water hydrogen isotope fractionation across all temperatures range from about -10 to $-50 \%$ (Savin \& Lee, 1988) so that combined with the oxygen isotope fractionation equations shown in Fig. 12, these data suggest that chlorite cannot have precipitated from meteoric waters at low temperatures.

Limited (four values) oxygen isotopic data obtained by Platt (1993) for Rotliegend porelining chlorites from the same area as the present study were all apparently much more enriched in $\delta^{18} \mathrm{O}$, the measured values ranging from 15.1 to $16.2 \%$ (SMOW). Based on these significantly higher $\delta^{18} \mathrm{O}$ values, Platt (1993) suggested chlorite precipitation from meteoric waters at surface temperatures or from more $\delta^{18} \mathrm{O}$ enriched waters during shallow burial. These higher $\delta^{18} \mathrm{O}$ values, however, are almost certainly due to contamination of the samples examined by Platt (1993) with substantial amounts of illite and quartz. The fact that illite contamination may cause the $\delta^{18} \mathrm{O}$ values to increase was discussed above, the two heaviest values obtained in the present study of 12.2 and $13.2 \%$ being from badly contaminated samples.

Although the chlorites from the present study span a large range of $\mathrm{Fe} /(\mathrm{Fe}+\mathrm{Mg}$ ) ratios, (perhaps as much as $80 \%$ of the compositional range normally encountered in chlorites), correlated isotopic trends were not evident. This suggests

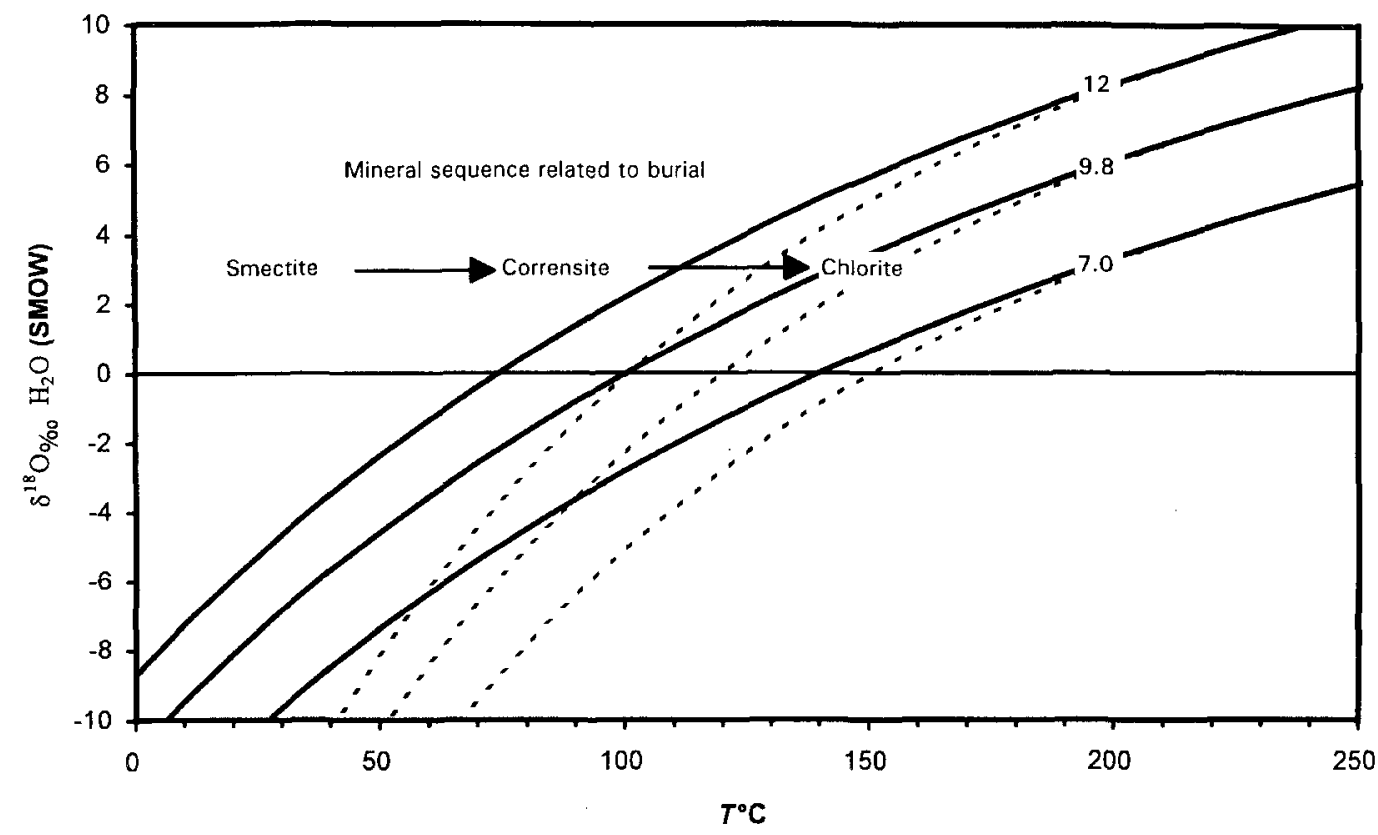

FIG. 12. Oxygen isotope fractionation curves for chlorite-water. Curves shown cover the general range of chlorite compositions from 7 to $12 \%$ and the mean value of $9.8 \%$. Solid lines are for the calculated eqn. 1 of this study, dotted lines for the experimentally determined equation of Cole (1985) as quoted in Savin \& Lee (1988). 
that all of the chlorites grew from, or equilibrated with, fluids of similar isotopic composition. It also suggests that different oxygen fractionation behaviour due to changes in chlorite chemistry may not be too significant, as was also implied by the calculated fractionation eqns. 1 and 2 for diagenetic chlorites, albeit without direct data on bond fractionations related to $\mathrm{FeMg}_{-1}$.

Finally, it was intended to determine whether trends in isotopic composition with grain size might reveal something about chlorite growth. Significantly, the differences observed with grainsize for the two samples analysed are almost equal to the entire range of the regional data for the 30 chlorite $2-6 \mu \mathrm{m}$ fractions. Furthermore, data for sample D59 show a definite trend of increasing $\delta^{18} \mathrm{O}$ with increasing grain-size, although no such trend is apparent in the data for sample D145. Although these limited data clearly indicate that grain-size effects may be of some considerable significance, it seems premature to speculate on the possible causes either in relation to the complex quasicrystal growth habit (Fig. 7) or growth history until other such data become available.

\section{CONCLUSIONS}

Regional chemical zonation of chlorite from the southwestern sector of the Rotliegend basin in northern Germany supports the proposal (Gaupp et al., 1993; Platt, 1993) that chlorite formation is related to the expulsion of $\mathrm{Mg}$-rich fluids from the basin centre shales and evaporites into the shoreline aeolian sandstones during shallow burial. Circumstantial evidence, however, suggests that chlorite was not the original pore-lining clay mineral. It is more likely that there has been an evolution from an original trioctahedral smectite to chlorite as a result of the temperature increase during burial. The actual formation of chlorite from precursor pore-lining clay minerals probably did not occur until temperatures reached $150-200^{\circ} \mathrm{C}$. Chlorite oxygen and hydrogen stable isotope results appear to be compatible with chlorite formation from waters with positive $\delta^{18} \mathrm{O}$ at the suggested temperatures.

Early formed, pore-lining, clay minerals are common in aeolian sandstones and can be of several different origins, their subsequent diagenetic evolution towards chlorite or illite depending on both the extent of burial and the nature of the fluids which enter the sandstones. If the proposed model of chlorite formation in the Rotliegend sandstones of northern Germany is more widely applicable, it suggests that the occurrence of $\mathrm{Mg}$-rich pore-lining chlorite is only to be expected in deeply buried aeolian sandstones that are likely to have received compactional waters from closely connected sabkha, playa lake, or evaporite deposits during shallow burial. In similar geological settings where burial has not been so deep, the model suggests that pore-lining smectite or corrensite are more likely to be found instead. Finally, the model implies that the junction between aeolian and playa lake facies is potentially an area where anomalously high porosity sandstones may be found.

\section{ACKNOWLEDGMENTS}

Thanks are due to Frank David, and Konrad Rockenbauch for access to samples and data on the Rotliegend of Northern Germany, and to BEB Erdgas und Erdöl for permission to publish the results. Bill McHardy is thanked for help with TEM. Financial support (Grant Nos. 20-30854.91 and 20-37363.93), and funding for the electron microprobe (Grant No. 21264789.89) at the University of Bern were provided by the Swiss national Science foundation. The SURRC is supported by the NERC and the Universities of the Scottish Consortium. The constructive criticism of an anonymous reviewer was appreciated.

\section{REFERENCES}

BaILEY S.W. (1988) Chlorites: structures and crystal chemistry. Pp. 347-404 in: Hydrous Phyllosilicates (exclusive of micas) (S.W. Bailey, editor) Reviews in Mineralogy, 19. Mineralogical Society of America.

BRINDley G.W. (1961) Chlorite minerals. Pp. 242-296 in: The $X$-ray Identification and Crystal Structures of Clay Minerals (G. Brown, editor). Mineralogical Society, London.

BORTHWICK J. \& HARMON R.S. (1982) A note regarding $\mathrm{ClF}_{2}$ as an alternative to $\mathrm{BrF}_{5}$ for oxygen isotope analysis. Geochim. Cosmochim. Acta, 46, $1665-1668$.

Clayton R.N. \& Mayeda T.K. (1963) The use of bromine pentafluoride in the extraction of oxygen from oxides and silicates for isotopic analyses. Geochim. Cosmochim. Acta, 27, 43-52.

COLE (1985) A preliminary evaluation of oxygen isotopic exchange between chlorite and water. Geol. Soc. Am. Abstr. Programs, 17, 550.

Dixon S.A., Summers D.M. \& Surdam R.C. (1989) Diagenesis and preservation of porosity in Norphlet 
Formation (Upper Jurassic), southern Alabama. Am. Assoc. Pet. Geol. Bull. 73, 707-728.

Fallick A.E., Macaulay C.I. \& Haszeldine R.S. (1993) Implications of linearly correlated oxygen and hydrogen isotopic compositions for kaolinite and illite in the Magnus Sandstone, North Sea. Clays Clay Miner. 41, 184-190.

FRIEDMAN I. \& SMITH R.L. (1958) The deuterium content of water in some volcanic glasses. Geochim. Cosmochim. Acta, 15, 218-228.

GAST R.E. (1991) The perennial Rotliegend saline lake in NW Germany. Geol. Jb. A119, 25-59.

Gaupp R., Matter A., Platt I., Ramseyer K. \& WALzEBUCK J. (1993) Diagenesis and fluid evolution of deeply buried Permian (Rotliegende) Gas Reservoirs, Northwest Germany. Am. Assoc. Petrol. Geol. Bull. 77, 1111-1128.

GLENNIE K.W. (1990) Introduction to the Petroleum Geology of the North Sea (K.W. Glennie, editor). 3rd edition. Blackwell Scientific Publications, Oxford.

HILLIER S. (1993) Origin, diagenesis, and mineralogy of chlorite minerals in Devonian lacustrine mudrocks, Orcadian Basin, Scotland. Clays Clay Miner. 41, 240-259.

HILliER S. (1994) Pore-lining chlorites in siliciclastic reservoir sandstones: electron microprobe, SEM and XRD data, and implications for their origin. Clay Miner. 29, 665-679.

HillieR S. \& Velde B. (1991) Octahedral occupancy and the chemical composition of diagenetic (lowtemperature) chlorites. Clay Miner. 26, 149-168.

Hogg A.J.C., Pearson M.J. \& Fallick A.E. (1993) Pretreatment of Fithian illite for oxygen isotope analysis. Clay Miner. 28, 149-152.

Kugler R.L. \& McHugh A. (1990) Regional diagenetic variation in Norphlet Sandstone: implications for reservoir quality and the origin of porosity. Trans. Gulf Coast Assoc. Geol. Soc. 40, 411-423.

Lee M., Aronson J.L. \& Savin S.M. (1989) Timing and conditions of Permian Rotliegende sandstone diagenesis, southern North Sea: K/Ar and oxygen isotopic data. Am. Assoc. Petrol. Geol. Bull. 73, $195-215$.

MEHRA O.P. \& JACKSON M.L. (1960) Iron oxide removal from soils and clays by a dithionite-citrate system buffered with sodium bicarbonate. Clays Clay Miner. 7, 317-327.

ORHAN H. (1992) Importance of dust storms in the diagenesis of sandstones: a case study, Entrada sandstone in the Ghost Ranch area, New Mexico, USA. Sed. Geol. 77, 111-122.

PlatT J.D. (1993) Controls on clay mineral distribution and chemistry in the early Permian Rotliegend of Germany. Clay Miner. 28, 393-416.

PLATT J.D. (1994) Geochemical evolution of pore waters in the Rotliegend (Early Permian) of northern Germany. Mar. Pet. Geol. 11, 66-78.

Robinson A.G., Coleman M.L. \& Gluyas J.G. (1993) The age of illite cement growth, Village Fields area, southern North Sea: Evidence from K-Ar ages and ${ }^{18} \mathrm{O} /{ }^{16} \mathrm{O}$ ratios. Am. Assoc. Petrol. Geol. Bull. 77, $68-80$.

Rossel N.C. (1982) Clay mineral diagenesis in Rotliegend aeolian sediments of the southern North Sea. Clay Miner. 17, 69-77.

Russel J.D., Birnie A. \& Fraser A.R. (1984) High gradient magnetic separation in soil clay mineral studies. Clay Miner. 19, 771-778.

SAVIN S.M. \& LEE M. (1988) Isotopic studies of phyllosilicates. Pp. 189-224 in: Hydrous Phyllosilicates (exclusive of micas) (S.W. Bailey, editor). Reviews in Mineralogy 19, Mineralogical Society of America.

WALKER J.R. (1993) Chlorite polytype geothermometry. Clays Clay Miner. 41, 260-267.

WARREN E. \& CURTIS C. (1989) The chemical composition of authigenic illite within two sandstone reservoirs as analysed by ATEM. Clay Miner. 24, $137-156$.

Whitney G. \& Velde B. (1993) Changes in particle morphology during illitization: an experimental study. Clays Clay Miner. 41, 209-218.

WILSON M.D. (1992) Inherited grain-rimming clays in sandstones from eolian and shelf environments: their origin and control on reservoir properties. In: Origin, Diagenesis, and Petrophysics of Clay Minerals in Sandstones (D.W. Houseknecht \& E.D. Pittman, editors). SEPM (Society for Sedimentary Geology) Spec. Pub. 47.

Winspear N.R. \& Pye K. (1995) The origin and significance of boxwork clay coatings on dune sand grains from the Nebraska Sand Hills, USA. Sed. Geol. 94, 245-254.

Ziegler K., Sellwood B.W. \& Fallick A.E. (1994) Radiogenic and stable isotope evidence for the age and origin of authigenic illites in the Rotliegend, southern North Sea. Clay Miner. 29, 555-565. 